\title{
Möglichst wenig peinlich: Zur Würde des Amtes des Bundespräsidenten
}

Maximilian Steinbeis

2012-03-19T08:29:53

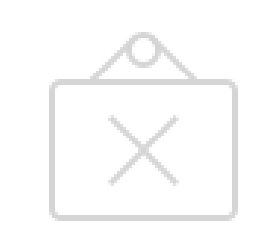

This photo is no longer available

Die Qual hat ein Ende. Das höchste Amt im Staate ist wieder besetzt, mit einem Mann, den zwar nicht alle lieben, aber doch alle respektieren. Joachim Gauck ist gewählt, am Freitag wird er vereidigt. Die viel beschworene „Würde des Amtes“, die schon unter Gaucks Vor-Vorgänger Horst Köhler und seinem kläglichen Abgang so böse gelitten hatte - jetzt, so scheint es, kann sie sich regenerieren. Jetzt wird alles wieder gut.

Wird es das? Genügt es wirklich, sich die individuellen Fehler der jeweiligen Amtsinhaber wegzudenken, und schon steht die Würde des Amtes wieder strahlend da? Tatsächlich wirkt es doch eher so, als hätten die jüngsten Affären nur sicht- und aussprechbar gemacht, was dieses Amt schon lange kennzeichnet: eine inhärente Neigung zur Peinlichkeit.

Es war schon immer leicht, sich über den Bundespräsident lustig zu machen. Er wohnt in einem großen Schloss, reist durch die Gegend und hält landauf, landab die feierlichsten Reden, von denen im Regelfall kein Mensch Notiz nimmt. Er unterschreibt Gesetze, die er nicht geschrieben, und ernennt Minister, die 
er nicht ausgewählt hat. Er ist Staatsoberhaupt, hat im Staate aber nichts zu melden. Während andere Verfassungsorgane die Geschicke des Landes lenken, bleibt dem Präsidenten jede Möglichkeit, sich jenseits kluger Worte nützlich zu machen, verwehrt. Wir sollen inm Autorität zuerkennen, die höchste im Staate sogar. Tatsächlich aber verweigert uns die Verfassung jeden Grund dafür.

Die Entmachtung des Präsidenten, so die verfassungsrechtliche Standarderklärung, war als Konsequenz aus dem warnende Beispiel des Weimarer Reichspräsidenten nötig. Der hatte als institutionalisiertes antiparlamentarisches Ressentiment seine Macht dazu eingesetzt, die Demokratie zu destabilisieren, und dazu sollte kein Staatsoberhaupt jemals mehr das Recht bekommen. Was niemand in Frage stellt. Nur, wenn das Amt potenziell so gefährlich und der demokratieverträgliche Spielraum, den man inm im politischen Kräftespiel lassen kann, so klein ist - warum schafft man es dann nicht einfach ab?

Tatsächlich halten manche Verfassungsrechtsexperten das Amt des Präsidenten in einer modernen pluralistischen Demokratie für entbehrlich. Aus ihrer Perspektive ist dieses Amt nicht mehr als ein anachronistischer Restposten einer versunkenen Verfassungswelt: Es nährt die Illusion, Politik könne „überparteilich“ sein und durch Einsatz moralisch gelenkter Vernunft das Richtige finden und tun, anstatt sich im politischen Meinungskampf immer bloß auf den kleinsten gemeinsamen Interessennenner zu einigen. Es tut so, als ließe sich der Integrationsbedarf einer so diversen und komplexen Gesellschaft wie der unseren mit öffentlich geäußerten Nachdenklichkeiten decken. An einer solchen Aufgabe kann eine einzelne Persönlichkeit, und sei sie noch so untadelig und weise, gar nicht anders als scheitern. Sie ist somit zur Peinlichkeit von Verfassungs wegen geradezu verdammt.

Vielleicht aber lässt sich diese Diagnose aber auch positiv wenden: Die Peinlichkeit entsteht durch das offensichtliche Missverhältnis zwischen Anspruch und Realität. Der Bundespräsident muss permanent so tun, als verkörpere er die tollsten Dinge, von der Einheit der Nation bis zur moralischen Vortrefflichkeit des Staates. Das tut er ganz offensichtlich nicht, und darin liegt das Peinlichkeitspotenzial seines Amtes. Vielleicht ist dies aber gar kein Schaden, im Gegenteil. Vielleicht besteht die „Würde des Amtes" sogar genau darin: das Kreuz der Peinlichkeit auf sich zu nehmen und, tja, in Würde zu tragen.

Was heißt das? Das heißt erstens, dass der Bundespräsident den Widerspruch zwischen Anspruch und Realität nicht zugunsten der Realität auflösen darf. Das ist Christian Wulff passiert, dem Moral-Normalo und Großburgwedeler Häuserkäufer mit den komischen Freunden. Wenn in Schloss Bellevue unter wehender Bundesflagge einer sitzt, der so tut, als sei doch gar nichts dabei, ein Politiker und Karrierist und kleiner Sünder allzumal zu sein, dann produziert er damit ein Ausmaß an Peinlichkeit, dass keiner lange aushält.

Das heißt aber zweitens, dass er auch nicht versuchen sollte, die Realität dem Anspruch anzupassen. Ein Bundespräsident sollte bei überdurchschnittlicher Rechtschaffenheit und Weisheit einen möglichst unterdurchschnittlich ausgeprägten Gestaltungsdrang mitbringen. Er hat nun mal keine Macht, und 
das weiß doch jeder. Die Peinlichkeitsnadel ist in der jüngeren Geschichte des Bundespräsidialamts immer dann besonders heftig ausgeschlagen, wenn der Amtsinhaber unbedingt Wirkung entfalten wollte - das Land wachrütteln, seine erschlaffenden Wachstumskräfte revitalisieren und dergleichen. Wenn Horst Köhler sich darauf beschränken hätte können, sympathisch zu lächeln, ruhig und besonnen dreinzuschauen und, ohne zuvor mit aschfahler Miene vor dem drohenden Untergang des Abendlandes zu warnen, den Bundestag aufzulösen, wenn die Politik es nun mal so will - wer weiß, vielleicht wäre er dann heute noch im Amt.

Vielleicht ist das der Maßstab, an dem ein Bundespräsident am Ende seiner Amtszeit seinen Erfolg bemessen kann: Möglichst wenig peinlich gewesen zu sein. In diesem Sinne hat Joachim Gauck die Chance, die Würde seines Amtes wieder herzustellen. Wenn er sie nutzt, wird er in die Geschichte eingehen: ohne große Taten, ohne große Worte, aber als großer Bundespräsident.

Foto: Bundeswehr-Fotos Wir.dienen.Deutschland, Flickr Creative Commons 